entire Arctic circle, just as the Arctic flora is now ; Asia, Japan, and North-West America being then continuous; that as the climate became cooler in the pliocene epoch, it was driven southwards along every meridlan, its descendants now existing in the localities above mentioned. It will be seen that these form a belt all round the globe, roughly speaking, between the 3 oth and 4oth parallels of latitude. Migration to some extent might have taken place along that belt, but the great migration I suggest was probably from north to south, and not from east to west, or vice versa.

The above theory is simply an adaptation of that given by Dr. Hooker for a similar dispersion of the existing Arctic flora, which replaced the temperate floras of Europe, Asia, and America; but which on the return of a temperate climate retreated northwards as well as up temperate and even tropical mountains, perishing, however, in the low lands.

George Hensloiv

\section{The Fertilisation of Orchids}

WHILE botanising this spring in Portugal, I was struck with the fact that scarcely one of the orchids-species of Ophrys principally-that I had collected for my herbarium, or exa. mined in the field, seemed to be fertilised, for none presented the least indication of having had pollen applied to its stigmatic surface; and I examined flowers in every stage of expansion, from the opening of the bud to the withered and shrunk up floral envelopes. Each one, I remarked besides, contained its own pollinia, their caudicles in their respective glands and in their natural position. I was so struck with this, that one day (March 3I) I gathered and examined forty-five different flowerheads, and of all these only one was found to have pollen-grains on its stigma, and all, the fertilised one included, had their pollinia intact. The locality was the Tapada d'Ajuda, or Royal Park, situated just outside the city walls of Lisbon, an inclosure containing many acres of land, clothed in spring with a rich flora, and a favourite entomological hunting ground, teeming witb Coleoptera, Hymenoptera, and the commoner Lepidoptera. Several of the orchids contained aphides, and a few harboured a species of small red ant.

On April 21 $\Upsilon$ again made similar observations, selecting the same place, as it was most accessible to me, and because several orchidea grew there in the greatest profusion. On this occasion I examined over thirty flowers-none of them the same as I had examined in March, for I had plucked these at the time, but there was not one that did not possess its pollinia, and, as on the previous occasion, none of them showed any appearance of having had pollen-grains in contact with their stignas.

Yct the Tapada, during the spring, produces these orchids by the thousand, vigorous, healthy, sweet-smelling plants, and in sunny days its air is perfectly alive with insect life, as I have said, of every kind.

Old Hall, Highgate, N.:

\section{New Meteor Radiant}

THE " two remarkable meteors" closely following each other, observed by Mr. Hope on May 13 (NATURE, vol. xvi. p. 43), proceeded most probably from a shower in the small southern constellation Crater. Your correspondent describes the point of first appearance as a little south of Arcturus. If this means about $7^{\circ}$ or $8^{\circ}$ below that star, then the observed courses accord well with the centre indicated, which is apparently quite a new radiant. From the Italian catalogue of $7,5 \mathrm{I} 2$ meteor paths (observed by Schiaparelli, Denza, and others in 1872 ) which I have lately been reducing, I found this shower at R.A. I70 , Dec. $10^{\circ} \mathrm{S}$. (near $\in-\theta$ Crateris) for May $3 \cdots 15$ from nine meteors.

Ashley Down, Bristo\}, May 27

W. F, DENNING

\section{OUR ASTRONOMICAL COLUMN}

ANTHELM'S STAR OF 1670.-The small star which is very close to the position of this object, as determined from the observations contained in Lemonnier's " Histoire Celeste," deserves to be closely watched, as there is more than a suspicion of its variation within narrow limits. Thus in August, 1872 , it was exactly equal to a star which follows it $12.5 \mathrm{~s}$. in R.A., $4^{\prime} 9$ to the north; while in November, 1874, it was as certainly fainter by half a magnitude. This small star precedes the variable $\mathrm{S}$.
Vulpecula $43^{\prime} 6 \mathrm{~s}$. , and is north of it $2^{\prime} \mathbf{I r}^{\prime \prime}$; two other small stars follow less than $2^{\prime}$ from the parallel, $22^{\prime} 4 \mathrm{~s}$. and $30^{\circ} 6 \mathrm{~s}$. respectively.

Prof. Schönfeld found the place of Anthelm's star from the observations of Hevelius and Picard,

R.A. 19 h. $4 \mathrm{Im} .37 \mathrm{~s}$. N.P.D. $63^{\circ} 2^{\prime} 3$ for $1855^{\circ}$.

The place of the suspicious star alluded to above is, for the same epoch,

R.A. Igh. $4 \mathrm{Im} .43^{\circ} 5$. N.P.D. $63^{\circ} 2^{\prime} 7^{\prime \prime}$.

It was meridionally observed at Greenwich in 1872 .

D'ARREST'S COMET.-As yet we hear nothing of observations of the short-period comet of D'Arrest, for which M. Leveau has worked so laboriously, with the view to facilitate its discovery at the present return. The intensity of light was at a maximum about May 22, but diminishes gradually during the summer. Nevertheless, early in August it is still of the same amount as when Prof. Schmidt discontinued his observations at Athens in December, 1870 , at which time he stated he could have followed it longer but for the want of an ephemeris. Subjoined are the comet's calculated positions during the absence of moonlight in the present month, for Paris noon :-

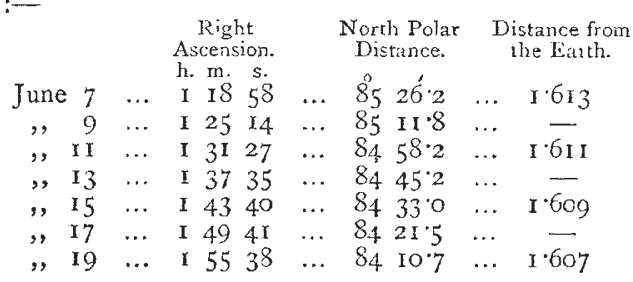

Though the comet will not arrive at its least distance from the earth during the present visit (1*396) until October 20, it passed its perihelion on May 1o. The period of revolution is now $2,4,34$ days, or $35 \frac{1}{2}$ days longer than at its last appearance in 1870.

The D'Angos Comet of I784.--Perhaps no person who has been occupied in astronomical observation and calculation has obtained for himself, rightly or wrongly, a more unenviable notoriety than the Chevalier D'Angos, who, in the latter part of the eighteenth century, was possessed of a small observatory in the island of Maita. From the unusual character of some of his statements his name came to be associated with anything in the way of observation that appeared to be apocryphal, and we find not only Zach was in the habit of terming doubtful assertions "Angosiades," but even Pastorff, who himself put upon record more than one suspicious statement, appeared to consider that he was establishing the good faith of an observation of a comet in transit across the sun's disc by declaring that it was not an observation made "à la D'Angos." We pass over on this occasion the reported observations by D'Angos in I784 and 1798 of a comet or planet upon the sun, with the view to presenting the reader with a brief outline of the actual state of a case that has been open to still greater suspicion, viz., his observation and calculation of what appears in some of our catalogues as the second comet of 1784 ; and we may be pardoned for bringing together here particulars which though probably known to those who have access to a good astronomical library, are not so likely to be within the cognisance of those who cannot command such a collection. And further, it is almost essential to bring the main points in the case into one view, to enable the reader to judge for himself whether D'Angos is deserving of the opprobrium which has been cast upon him or not.

Writing from Malta on April I 5, 1784, D'Angos apprised Messier at Paris that he had discovered a comet in Vulpecula on April I I, and he inclosed two approximate positions observed on the mornings of these days. He stated that the comet was very small, without tail, and with only "a slight appearance of nebulosity." - Messier 